\title{
Elastic sealants for surgical applications
}

Nasim Annabi ${ }^{1,2,3,4}$, Kan Yue ${ }^{2,3}$, Ali Tamayol ${ }^{2,3}$, and Ali Khademhosseini ${ }^{2,3,4,5,6}$

${ }^{1}$ Department of Chemical Engineering, Northeastern University, Boston, MA, 02115-5000, USA

${ }^{2}$ Biomaterials Innovations Research Center, Department of Medicine, Brigham and Women's Hospital, Harvard Medical School, Boston, MA, USA

${ }^{3}$ Harvard-MIT Division of Health Sciences and Technology, Massachusetts Institute of Technology, Cambridge, MA, USA

${ }^{4}$ Wyss Institute for Biologically Inspired Engineering, Harvard University, Boston, MA, USA

${ }^{5}$ Department of Biomedical Engineering, Biomedical Engineering, The University of Texas at Austin, Austin, TX, USA

${ }^{6}$ Department of Physics, King Abdulaziz University, Jeddah 21569, Saudi Arabia

Correspondence and requests for materials should be addressed to Ali Khademhosseini (Email: alik@rics.bwh.harvard.edu, Tel: 001-617-768-8395 Fax: 001-617-768-8477)

\begin{abstract}
Sealants have emerged as promising candidates for replacing sutures and staples to prevent air and liquid leakages during and after the surgeries. Their physical properties and adhesion strength to seal the wound area without limiting the tissue movement and function are key factors in their successful implementation in clinical practice. In this contribution, the advances in the development of elastic sealants formed from synthetic and natural materials are critically reviewed and their shortcomings are pointed out. In addition, we highlight the applications in which elasticity of the sealant is critical and outline the limitations of the currently available sealants. This review will provide insights for the development of novel bioadhesives with advanced functionality for surgical applications.
\end{abstract}




\section{Introduction}

Current technologies for reconnecting and sealing tissues after surgical procedures such as sutures, wires, and staples have several limitations, particularly in minimally invasive procedures. For example, the use of suture for wound closure is time consuming, may cause further tissue damage, result in infection, and do not provide immediate sealing to stop body fluid and air leakages. The application of surgical adhesives is a convenient alternative method for wound closure because of their characteristics, such as simple implementation procedure, shorter time, less painful to patients, and no need for removal. Towards this goal, various types of surgical materials have been used for sealing, reconnecting tissues, or attaching devices to the tissues [1].

Surgical sealants are commonly used to prevent leakage of fluid and/or gas from a surgical incision. Sealants can be formed by using natural or synthetic polymers, or a combination of both. The market for surgical sealants and hemostats is growing rapidly from $\$ 4$ billion in 2012 to $\$ 7$ billion in 2017, worldwide [2]. Although several tissue adhesives are commercially available, none of them are ideal surgical sealants for repairing elastic and soft tissues such as wounded lungs, heart, and blood vessels. It is extremely challenging to achieve significant adhesion to soft tissues while minimizing toxicity, tissue damage and other side effects of the sealing materials. Another limitation is the low adhesion strength of the most commercially available sealants in wet and highly dynamic environments in the body at the presence of blood. Most of the clinically available glues and sealants do not offer both elasticity and good adhesion. For example, cyanoacrylates have high stiffness and adhesion strength but are not elastic. On the other hand, fibrin-based sealants are more flexible with low stiffness and adhesion strength. There is a large unmet need for surgical sealants, which can provide flexibility without compromising strength and can stop body fluid and air leakages in different procedures such as lung and cardiovascular surgeries.

Recently, extensive research efforts have been made to engineer biocompatible, biodegradable, and flexible sealants for the formation of leak-free closures in soft tissues [3-5]. The sealant materials are required to be elastic and compliant to allow normal function and movement of elastic native tissues such as lungs, skin, blood vessel, and heart tissues. In this review, various types of elastic surgical sealants made of natural and 
synthetic polymer are discussed. These include flexible synthetic sealants based on polyurethane (PU), polyethylene glycol (PEG), and polyester, naturally occurring or composite sealants made of proteins or polysaccharides. In addition, recent development in the synthesis of mussel inspired elastic sealants with high adhesive properties is reviewed. Finally, some clinical applications for the elastic sealants in various surgical procedures are highlighted.

\section{Synthetic polymer derived elastic sealants}

Synthetic-based elastic tissue adhesives have attracted significant attention as suitable wound closure techniques for clinical applications due to their strong adhesive strength and tunable mechanical properties. In particular, elastic sealants based on synthetic polymers can be used as sutureless wound closure for elastic and soft tissues such as lungs, heart, and blood vessels. Some examples of this class of adhesives include PUbased, PEG-based, and polyester-based adhesives.

\subsection{Polyurethane-based tissue adhesives}

PU-based biomaterials have been widely used sealants due to their high elasticity and strong adhesion to the tissues. In the prepolymer form, urethane can react with the amino groups of proteins of the tissues to create urea linkages and subsequently promote adhesion strength to the tissues [6]. PU-based biomaterials can be synthesized in biodegradable forms through modification with natural molecules. For example, Ferreira et al. synthesized a biodegradable PU-based adhesives through modification of castor oil with isophorone diisocyanate (IPDI) [7]. They also formed PU-based adhesives through reaction between polycaprolactone (PCL) diol and IPDI or hexamethylene diisocyanate (HDI) [6]. The engineered PU-based adhesives promoted adhesion to the tissue but induced thrombosis as shown by haemolysis tests, which can limit its clinical applications [6]. To overcome this limitation, the group later developed a photocrosslinkable PU-based adhesive through modification of PCL with 2isocyanatoerhylmethacrylate (IEMA) [8]. Their experimental data showed that the synthesized material was slightly haemolytic (within the acceptable limit) after directly 
applying with existence of blood. Moreover, haemolysis was stopped when the material were extracted with PBS solution [8].

Previous studies have shown that the use of PU-based tissue adhesives had no toxic degradation products after surgical procedures such as orthopedic and renal surgery and pancreatic occlusion. PU-based adhesives have been also used in cosmetic surgery. For example, a sprayable PU adhesives (TissuGlu, Cohera Medical Inc., Pittsburgh, PA) was used for abdominoplasty surgery to avoid seroma formation in a canine abdominoplasty model [9]. It was shown that TissuGlu created strong bonding between tissue layers and supported natural healing process without any toxic effects [9]. Despite significant improvements in the formation of nontoxic and biodegradable PU-based surgical materials, safety concerns still exist for their utilization in surgical procedures.

\subsection{PEG-based sealant}

PEG-based biomaterials have been widely used as fluid barriers and hemostatic adhesives. There are several commercially available PEG-based surgical materials including Duraseal (Covidien Inc., Mansfield, MA), Coseal (Cohesion Technologies, Inc., Palo Alto, CA), FocalSeal (used to be produced by Genzyme Biosurgery, Inc., Cambridge, MA but it is currently discontinued), and AdvaSeal (Ethicon Inc., Johnson \& Johnson Medical KK). Duraseal is made of PEG ester and trilysine amine solutions and has been used for neurosurgeries to prevent cerebrospinal fluid leakage after cranial and spinal operations [10-13]. For example, Preul et al. applied Duraseal on an incision of a cranial dura and arachnoid created in dogs to seal the dural gaps. It was shown that animals treated by the sealant had normal dural healing process with no adverse effects on the brain. In addition, the sealant reduced cerebrospinal fluid leakage and consequently facilitated surgical reexploration [13]. Kim et al. also performed a clinical study to use Duraseal as an adjunct spinal sealant to sutured dural repair. Their study confirmed that the sealant provided watertight closure during spinal surgeries, which was better than the standard care technologies (suture only) for dural closure in spine surgeries [10]. In another clinical study, the suitability of Duraseal for reducing scar tissue and post-operative pain after lumbar microdiscectomy was evaluated [11]. The results on 21 patients showed that Duraseal was safe and reduced post-operation pain as 
compared to the control group. In addition, the patients treated with the sealant had normal wound healing process with no post-operative complications [11].

FocalSeal is another PEG-based sealant, which was developed to stop air leaks after lung surgeries. It is made from a primer and an acrylated PEG-based sealant [14-16]. The primer layer should be first applied to provide good adhesion to the tissue, followed by the sealant layer to provide adequate mechanical properties and maintain the sealing during the tissue movement. Finally, the sealant is crosslinked by photopolymerization using visible blue light. It was shown that the engineered sealant had elastic modulus of $28 \mathrm{kPa}$, which was close to human lung tissue (29.4 kPa) and extensibility up to $700 \%$ [14]. The results of clinical study demonstrated that Focalseal function as an adjunct to the traditional closure techniques to seal intra-operative pulmonary leaks [17]. In addition, the use of this sealant significantly reduced post-operative air leaks leading to the shorter hospitalization [17]. The production of Focalseal was discontinued due to its poor adaption by surgeons. Coseal is also a commercially available PEG-based sealant, which is made of two 4-arm PEG with glutaryl-succinimidyl ester and thiol terminal groups [18]. The reaction between thiol groups and the carbonyl groups of the succinimidylester can form covalent bonds between PEG molecules after mixing [18]. Coseal has been employed in vascular surgery to seal suture lines and stop bleeding [19]. PEG-based sealants have several advantages including biocompatibility, controlled degradability, flexibility, and relatively high adhesion strength. However, high swelling ratio of PEG-based sealants may cause pressure build up on the surrounding tissues when applied in closed cavities [20].

\subsection{Other synthetic polymer-based sealant}

Different types of polyester-based sealants with elastic properties have been developed for surgical applications to reduce the incidence of fluidic or air leaks. For example, Chen et al. developed a surgical sealant based on poly(glycerol sebacate) (PGS) and lactic acid (LA) [3]. The use of LA improved the cytocompatibility of the engineered sealant compared to PGS alone. The sealant could be applied at $45^{\circ} \mathrm{C}$ and solidified at $37{ }^{\circ} \mathrm{C}$ to form an elastic gel by exposing to a cold gas. It was shown that the fabricated sealant had higher adhesion strength to the tissues compared to both fibrin glues and synthetic 
sealants such as Pleuraseal [3]. Photocurable elastomers based on PGS with strain between 42-189\% and Young Modulus of 0.05-1.38 MPa were also developed through acrylation of PGS [21]. The engineered synthetic elastomer had been recently used for cardiovascular surgeries to close defects in heart and arteries and stop bleeding [22].

Sealants based on other synthetic polymers have been also developed to close wound in different surgical procedures. For example, in a recent study, a polyvinyl alcohol (PVA)-based tissue adhesive for wound closure was prepared via sequential enzymatic reactions that were activated by glucose in the wound exudate [23]. The hydrogel was formed in situ after applying the mixed solution of a PVA derivative functionalized with phenolic hydroxyl moieties (PVA-Ph), together with two enzymes, i.e., glucose oxidase (GOx), and horseradish peroxidase (HRP) on the wound (Figure 1). The results of mechanical testing demonstrated that the engineered PVA-based adhesives had high durability toward both stretching and compression. In addition, the hydrogel was effective in closing full-thickness wounds in rats as compared to commercially available hydrogel-based wound dressing [23].

Synthetic sealants can be easy modified and generally have higher mechanical strength and tissue-bonding properties compared to natural derived sealants. However, potential cytotoxicity, chronic inflammation, low adherence to the wet tissues and, in some cases, long curing time are some of the limitations associated with synthetic-based sealants [6].

\section{Sealants based on natural biopolymers}

Sealants derived from natural biopolymers possess many advantages over synthetic materials including superior biocompatibility, reduced immune response, and in vivo degradability. Natural biopolymers can be classified into polysaccharides and polypeptides (including proteins), which are built up by sugar or amino acid units, respectively. Degradation of biopolymers results in small molecular byproducts that can be easily absorbed by the body. Therefore, developing sealants derived from natural polymers has been an active research area during the past two decades and some of the developed sealant systems have been approved by Food and Drug Administrative (FDA) for certain surgical applications. In the following section, we will describe a brief 
summary of the reported sealants containing at least one kind of biopolymers as the essential functioning components.

\section{1. Polypeptide/protein-based sealants}

\section{Fibrin sealants}

Fibrin-based sealants are one of the earliest surgical glues used in medical applications [24]. The working mechanisms of fibrin-based sealants are similar to the series of bioreactions in the final stages of blood clotting $[25,26]$. Typically, fibrin sealants are composed of two major components obtained from pooled human plasma, fibrinogen and thrombin. Fibrinogen is a large soluble glycoprotein existing in plasma and plays key roles in the formation of blood clots. Thrombin will activate fibrinogen and convert it to fibrin monomers, which are further crosslinked by Factor XIII to form insoluble clots (haemostasis). Since these biological processes are promoted by the calcium ions, many fibrin sealants also contain a small amount of calcium ions to accelerate the reactions [27].

Fibrin sealants can take effect in relatively short times, form covalent connections with surrounding tissues via the amidation reactions, and also function as hemostats. Therefore, fibrin sealants have been tested for a variety of different applications in surgeries as both tissue sealants and hemostats. To date, fibrin sealants are commercially available under different brand names, such as Tisseel (Baxter Inc., Denmark), Evicel (Ethicon Inc., Bridgewater, NJ), Crosseal (OMRIX Biopharmaceuticals Ltd. Israel), and Hemaseel (Heamacure Corp., Canada), among many others [28]. Although fibrin-based sealants are popular for different surgical applications, they have some disadvantages that limit their applications and even raise safety concerns. First, they are manufactured from human plasma from blood donators and therefore, are more expensive and less available than synthetic materials. Possible disease transmission associated with blood products is another major concern limiting their widespread applications. Most importantly, fibrin sealants have only poor to moderate adhesion properties, especially in wet environments or wounds with abundant amounts of body fluids [29]. Their mechanical properties are not strong enough for many elastic tissues. As a result, in many cases fibrin sealants are only used in combination of traditional techniques such as sutures or staples [29]. 
Recently, fibrin sealants based on new photochemical crosslinking reactions have been reported, providing insight to develop new fibrin sealants with enhanced physical properties. Covalent crosslinking of fibrin (and many other proteins or polypeptides) can be achieved via the formation of dityrosine linkers between two tyrosine residues catalyzed by a ruthenium compound and persulfate salt [30]. Photo-irradiation was required to activate the metal catalyst, resulting in high crosslinking efficiency and very fast curing (Figure 2a). Elvin et al. applied this chemistry in preparing highly elastic, crosslinked protein/polypeptide biomaterials including recombinant pro-resilin [31], fibrinogen $[32,33]$, and gelatin $[34,35]$. In particular, the crosslinked native fibrinogen showed a five-fold increase in adhesion strength compared with commercial fibrin sealant Tisseel [32]. Mechanically, photocrosslinked fibrinogen-based hydrogels showed enhanced tensile strength compared to normal fibrin-based sealants with an ultimate tensile strength of $45 \mathrm{kPa}$ and the breaking of over $60 \%$. Moreover, the maximum strength was reached within $20 \mathrm{sec}$ light illumination, and the resulting glues showed low cytotoxicity as confirmed by in vitro experiments. Later, Elvin et al. further studied the adhesion properties and assessed the efficacy and safety of this photocrosslinkable fibrinogen sealant in animal models [33]. Upon photocrosslinking with the catalyst system, fibrinogen sealant readily formed efficient bonding to the surrounding tissues via dityrosine bond formation with many other proteins existed in the extracellular matrix (ECM). Subcutaneous implantation studies in rat models indicated a degradation time of about 8 weeks with moderate inflammatory response. Wound incision experiments also showed that the tensile strength of the healed skin was comparable to unwounded skin after 7 weeks, which was comparable to Tisseel [33]. These studies provided insights to design of novel rapidly polymerizable fibrin-based sealants with improved adhesion strengths and high elasticity for surgical applications.

\section{Collagen- and gelatin-based sealants}

Collagen is one the most abundant structural proteins in connective tissues in animals. Collagen is also a major component of ECM that supports the resident cells. Thus, collagen-based biomaterials have been widely studied in many biological applications [36]. Collagen molecules can be obtained from various sources of mammalian animals, 
and possess much lower disease transmission risks compared to fibrinogen [37]. Fibrous or porous collagen scaffolds can absorb blood and other molecules that promote blood coagulation, and also induce factors in the blood clot process [38]. Sealants that combine both bovine collagen and bovine thrombin have been approved by FDA [28]. These surgical sealants are quite similar to the fibrinogen-based sealants and work as adhesive matrix to provide additional clotting factors to stop bleeding. These products could offer a less expensive alternative compared to fibrin-based hemostats.

Gelatin is a mixture of polypeptides derived from the irreversible hydrolysis of collagen. Depending on the conditions of hydrolysis and animal source, composition and molecular weight of gelatin could vary to certain extent. The hydrolysis treatment partially breaks down the ordered strands structures of collagen, making gelatin easier towards further physical processing and chemical modifications. The basic compositions and biochemical properties of gelatin, however, are still quite similar to collagens in many aspects. The earliest trials to develop gelatin-based sealants utilized the reactions between primary amino groups on the lysine residues in gelatin with formaldehyde to form a covalent bond. Resorcinol was also added to increase the adhesion strength, resulting in the so-called gelatin-resorcinol-formaldehyde (GRF) recipe [39]. Due to the well know toxicity of formaldehyde, glutaraldehyde was later added to the gelatin sealant as the crosslinker, known as the gelatin-resorcinol-formaldehyde-glutaraldehye (GRFG) glue [39-41]. Mechanisms for the covalent bonds formation in these gelatin-based sealants are quite complicated. Three major reactions occurring in the process are shown in Figure 2b including conjugation between formaldehyde and gelatin (Figure 2b, i), crosslinking reaction between glutaraldehyde and gelatin via the Schiff base formation (Figure 2b, ii), and formation of a network structure by resorcinol and formaldehyde (Figure 2b, iii). Although high adhesion strength could be achieved, the major concern about GRF and GRFG sealants are the toxicity of both formaldehyde and glutaraldehyde.

To overcome this limitation, Ikada et al. reported the in situ formation of a tissue adhesive from a mixture of gelatin and $N$-hydroxysuccinimide (NHS)-ester functionalized poly(L-glutamic acid) (Figure 2c) [42]. Adhesion properties of this semisynthetic sealant were found to be higher than a fibrin-based sealant that was used as control, indicating potential applications of the engineered sealants in surgical 
applications. Later, Matsuda et al. applied this chemistry to crosslink gelatin with a small molecular crosslinker, disuccinimidyl tartrate [43, 44]. In this study, gelatin was modified by a series of different aliphatic acids to increase hydrophobicity and thus tissuepenetrating capability $[43,44]$.

A photochemical crosslinkable gelatin adhesive was also synthesized by Matsuda $e t$ al., which was applied in combination with a hydrophilic diacrylated polyethylene glycol (PEGDA) polymer [45]. Modification of gelatin with photo-reactive groups such as UV light-responsive benzophenone moieties or visible light-responsive xanthene dyes was achieved via the water-soluble carbodiimide chemistry. Light illumination upon the mixture of the modified gelatin and PEGDA quickly resulted in crosslinked hydrogels that showed strong adhesive properties and the ability to stop bleeding in a rat liver model [45]. In vivo biocompatibility and degradation studies were also performed to demonstrate the potential applications of the photo-curable gelatin sealants [45]. Another photocrosslinkable gelatin sealant was synthesized by Elvin et al., where they applied the Ru-catalyzed, photo-oxidation reaction of tyrosine residues as described above (Figure 2a) in gelatin and observed the formation of a highly elastic, nontoxic gelatin hydrogel in a short time [34]. High elasticity of the gelatin-based sealants was demonstrated with an extension to break larger than $650 \%$ and adhesive stress at break larger than $100 \mathrm{kPa}$. Physical properties of the resulting gelatin-based sealants could be tailored by changing tyrosine content of gelatin, concentration, and light exposure time. In vivo studies in a sheep model confirmed that this gelatin-based sealant could stop blood and air leakages in lung tissue with minimal inflammatory responses [34]. This sealant was also tested to seal surgical incisions in gastrointestinal (GI) tract surgeries in rabbits, demonstrating high adhesive strength (over $100 \mathrm{kPa}$ ) and no inflammation for up to 28 days after application [35].

Inspired by the fibrin sealants that mimicked the biochemical reactions in blood coagulation cascade, enzyme-catalyzed crosslinking reactions were also investigated to develop gelatin-based sealants [46-48]. A calcium independent microbial transglutaminase (mTG) was tested in crosslinking gelatin solution via the reaction between the glutamine and lysine residues (Figure 2d). The gelation time could be controlled within several min to produce hydrogels with Young's Modulus comparable to 
fibrin sealants. Lap-shear adhesion strength, however, was determined to be significantly higher than the fibrin-based sealants [47]. mTG-catalyzed gelatin sealants were subsequently studied in vivo in rat models for ophthalmic applications, demonstrating no cellular damage to rat retinal tissue and strong adhesion to wet retinal tissue [48].

\section{Albumin-based sealants}

Albumin refers to a family of globular proteins found in blood plasma, and can be obtained from different animal sources. Several types of albumin-based sealants have been developed based on similar reactions as discussed above. For example, BioGlue (CryoLife Inc., Kennesaw, GA) is a commercial sealant with FDA approval as hemostats in vascular and cardiac surgeries. It is made of bovine albumin and glutaraldehyde using a similar reaction as shown in Figure 2b, ii. The adhesion strength of the glue could be optimized by varying the ratio and concentrations of the two components [49]. Concerns about the biosafety of glutaraldehyde could arise for Bioglue in for internal use.

Another commercialized albumin-based sealant is Progel (Davol Inc., Woburn, MA) developed to prevent air leakage in lung surgeries. Progel is a composite sealant containing human albumin and a PEG crosslinker with two NHS activated ester groups [4, 50]. Upon mixing, the primary amine groups on lysine residues in albumin quickly react with the succinimidyl succinate groups and form a crosslinked structure within one min, which is similar to the reaction shown in Figure 2c. It was shown that Progel could effectively stop pleural air leakage and degrade relatively fast in vivo without severe immune responses $[4,50]$. Its applications in lung surgeries will be discussed in details in the following sections.

\subsection{Polysaccharide-based sealants}

Polysaccharides are a large family of biopolymers composed of different combinations of monosaccharide (sugar) building blocks. They vary in the structure, chemical linkage, molecular weight, and functional groups of the monosaccharide monomers. As a natural polymer, polysaccharides have been widely used in numerous medical, pharmaceutical and food products. 


\section{Chitosan-based sealants}

Chitosan is a polysaccharide derived from chitin, which is composed of $\mathrm{N}$ acetylglucosamine building blocks via beta-1,4-glycosidic linkages and is typically obtained from the exoskeleton of arthropods, such as crabs, lobsters and shrimps, as well as the cell walls of fungi. Partial hydrolysis (deacetylation) of the acetyl amide groups releases some free amine groups and results in chitosan.

Due to the relatively poor solubility of chitosan, Ishihara et al. reported a chemically modified chitosan derivative by reacting chitosan with lactobionic acid with the presence of a water soluble carbodiimide (Figure 3a, i) [51, 52]. Azido groups were then introduced to the water-soluble chitosan by reacting with 4-azidobenzoic acid via the same chemistry (Figure 3a, ii). The resulting modified chitosan could be photocrosslinked by exposing to UV light to form chitosan-based sealants. Under UV irradiation, the azido groups would decompose to release $\mathrm{N}_{2}$ and form highly reactive nitrene groups, which will simultaneously dimerize to generate azo-linkages. In vitro cell culture studies confirmed nontoxicity of the engineered chitosan sealants. In a following study from the same group, this chitosan sealant was further tested in a mouse model for wound closure [53]. Significantly accelerated wound closure and advanced granulation tissue formation were observed, suggesting promising application of this chitosan-based sealant for clinical applications.

Later, Moratti et al. reported the synthesis of succinylated chitosan by reacting chitosan with succinic anhydride (Figure 3a, iii). This modified chitosan showed enhanced water solubility. When mixing with dextran aldehyde obtained from oxidation of dextran (see below for details), a gel was formed via the imine bond formation between the amino groups and aldehyde groups, which showed excellent haemostatic and adhesive properties in animal models [54]. Park et al. developed a synthetic procedure to graft tyrosine modified PEG chains through the amino groups on chitosan (Figure 3a, iv) [55]. Grafted PEG chains largely increased the solubility of chitosan and provided reactive tyrosine groups to form crosslinked network structure. With the presence of a HPR and hydrogen peroxide, the chitosan solution quickly formed a gel via the dityrosine bond formation. Adhesion strength of the engineered chitosan-PEG composite sealant was several times higher than fibrin sealants. Moreover, in vivo studies in a rat model 
demonstrated that the fabricated chitosan-based sealant showed superior healing ability in skin incision comparing to suture, fibrin glue and cyanoacrylate [55].

Recently, Zhao et al. reported the formation of a composite hydrogel based on thiol containing chitosan (Figure 3a, v) and maleimide containing $\varepsilon$-polylysine [56]. The Michael addition reaction between thiol and maleimide groups led to the in situ formation of a crosslinked hydrogel upon simply mixing of the two components. This chitosanbased composite sealant showed four times higher adhesion strength compared with fibrin glue. Synthesis of thiol containing chitosan (Figure 3a, vi) was also reported by Lee et al. to chemically graft hematin, which was an Fe(III) containing porphyrin, with chitosan. The resulting chitosan was used as an enzyme-mimetic biocatalyst to accelerate the crosslinking of catechol-modified polymers [57].

\section{Dextran-based sealants}

Dextran refers to a relatively complex polysaccharide with some branched structures. Its linear part is composed of glucose building blocks via the alpha-1,6-linkages. Different from chitosan, which is a polyglucosamine, there are no reactive amino groups in dextran. One modification strategy reported for dextran-based sealants replies on the selective partial oxidation of dextran to introduce aldehyde groups (Figure $\mathbf{3 b}$ ), which can react with amino group to form imine linkages (similar to the reaction shown in Figure 2b, ii) and result in the formation of hydrogels. Other modification methods include introducing methacrylate functional groups to crosslink with thiol crosslinkers [58], or preparing enzyme-crosslinkable dextran-tyramine conjugates [59]. Araki et al. studied the aldehyde functionalized dextran-based sealant by mixing it with $\varepsilon$-polylysine [60, 61]. Gelation was achieved via the Schiff base bond formation. Adhesion properties of this dextranbased lung sealant was evaluated in vivo and it was found that it had better adhesion than the fibrin glue control. Biodegradability and histotoxicity were also tested in a dog model. Inflammatory reactions were largely reduced 4 weeks after application, and the sealant could be degraded on the lung tissue within 3 months [60, 61]. Bhatia et al. reported another tissue sealant by combining the aldehyde-containing dextran with an 8-arm amine-endcapped PEG crosslinker [62]. Cytotoxicity and inflammatory properties were tested in vitro using 3T3 fibroblast cells and J774 macrophage cells. The experimental 
results suggested that this dextran-PEG tissue adhesive was non-cytotoxic and did not induce inflammatory response [62].

\section{Chondroitin sulfate-based sealants}

Chondroitin sulfate is a sulfated polyglucosamine typically found as the structural component in cartilage ECM and many other tissues in the body. Due to its key biological roles in the formation and function of cartilage tissues, sealants based on chondroitin sulfate have been developed and tested to regenerate the connections between cartilage tissue and biomaterials, as well as in corneal wound healing. Since there are multiple reactive sites in chondroitin sulfate, different modification strategies have been developed to introduce various functional groups, including methacrylate groups, aldehyde groups, and NHS-activated ester groups (Figure 3c). Elisseeff et al. reported the synthesis of a photocrosslinkable chondroitin sulfate derivative by reacting with glycidyl methacrylate at room temperature (Figure 3c, i) [63]. Hydrogels were feasibly obtained by UV crosslinking with a photoinitiator. Morphological and mechanical, and biological properties of the chondroitin sulfate-based hydrogels were studied. Later, they developed a different chemical modification method of chondroitin sulfate by partially oxidizing the polysaccharide with periodide to introduce aldehyde groups, similar to the reaction used for dextran sealants [64]. A synthetic polymer, poly(vinyl alcohol-co-vinyl amine), was used in combination with the aldehyde-bearing chondroitin sulfate to form a hydrogel-based sealant. They used the engineered chondroitin sulfate-polymer sealant in a rabbit model to seal corneal incisions. The fabricated sealant showed superior performances compared with the traditional suture techniques in ex vivo studies [64].

In another study, chondroitin sulfate was modified with both methacrylate and aldehyde groups on the backbone to form a chondroitin sulfate-based tissue sealant that chemically bridged tissue proteins and the implanted biomaterials via a two-fold covalent linkages [65]. The adhesive solution was applied to the surface of the cartilage tissue, followed by a second layer of pre-polymer solution with a photoinitiator (Figure 4a). Upon photocrosslinking, the chondroitin sulfate acted to integrate the cartilage tissue and the implanted hydrogels together, which could remain in vitro for several weeks. Enhanced adhesion of the applied biomaterials to the cartilage tissue was further 
confirmed by in vivo subcutaneous implantation in a rat model (Figure 4b-c). A strong adhesion between the implanted hydrogel and the native cartilage tissue was observed even after 5 weeks of implantation. Moreover, proteoglycan production was observed both in the implanted hydrogel and at the interface (Figure 4d), which suggested a useful method to enhance the preformation of implanted materials for efficient tissue repair [65].

Recently, Strehin et al. reported the preparation of NHS-activated chondroitin sulfate derivative by modifying the carboxylic acid groups to introduce the activated ester groups [66, 67]. This modified chondroitin sulfate could react with a 6-arm aminecontaining PEG crosslinkers to form a hydrogel-based sealant via the amide bonds. It was also suggested that when applied to wounded tissues, the NHS-activated chondroitin sulfate would also react with the amino groups on the local tissue surfaces. Physical properties of the chondroitin sulfate-PEG hydrogel were influenced by the concentration, degree of NHS functionalization, as well as the $\mathrm{pH}$ value of the precursor solutions. Minimal inflammatory response was observed after subcutaneously implantation in a rat model, indicating the suitability of the engineered composite hydrogels for wound healing and regenerative medicine [67].

\section{Mussel inspired elastic sealants}

During the past two decades, a new family of adhesives has been developed inspired by the observation of strong adhesion of some marine creatures, such as mussels to solid surfaces. Mussels can secrete a protein adhesive that works under typical marine environments and does not lose the adhesion properties even in saline [68]. Thus, such adhesives can address the key challenges for the development of water-resisted tissue sealants $[69,70]$. It is now known that the main component of this bio-adhesive is a complex mixture of proteins featured by an extremely high content of a particular amino acid, L- $\beta$-3,4-dihydroxyphenyl- $\alpha$-alanine, or DOPA [71]. This DOPA residue is considered as the product from oxidation of the tyrosine residues. The working mechanisms of this bio-adhesive are complicated, which involve a series of reactions between different functional groups [72]. It is known that diquinone intermediates are formed by oxidation of the DOPA residues, which could react with, for example, amino and thiol groups via Michael addition, or certain metal ions via coordination [73]. 
The unique bio-adhesive properties of mussels have attracted much attention to develop novel sealants for adhesion to wet surfaces. Early trials include extracting the secreted proteins from mussels [74]. While this approach helped with understanding the mechanism of the formation of this material, extraction could only provide limited amount of it that was not cost-efficient. Synthetic polypeptides with designed sequences have also been studied to investigate the structure-property relationships in this class of sealants $[70,75]$. In addition, recombinant DNA technology has been used to prepare mussel inspired protein sealants [76, 77]. However, the expression of the key adhesive proteins typically resulted in low yield and purity, which limited the practical applications of the recombinant DNA strategy.

As a result of the difficulties in directly preparing DOPA-containing proteins, biocompatible synthetic/natural polymers modified with DOPA motifs are promising targets for developing DOPA-based sealants. To date, the DOPA moieties have been successfully incorporated within a variety of polymers, including both synthetic polymers or modified natural polymers. The chemical approaches towards developing DOPAcontaining polymers differ significantly in different systems. In this section, we will briefly summarize progresses in DOPA-containing polymers as tissue sealant materials.

In one study, Deming et al. reported the synthesis of polypeptides with tunable DOPA contents via ring-opening polymerization of $N$-carboxyanhydride (NCA) monomers prepared from DOPA and lysine by phosgenation [75]. Protected NCA monomers were copolymerized to form high molecular weight polymers with excellent conversions. Feasible control over DOPA content could be achieved by changing the feed ratio of the two monomers. Systematic studies on several factors that might influence the adhesion properties were performed, including copolymer composition, concentration, selection of oxidation reagents, and curing temperature [75]. Results showed that the synthetic polypeptides possessed comparable adhesion properties with mussel adhesives to several substrates under optimized crosslinking conditions $[72,75,78]$.

Wilker et al. later reported a simplified system as mussel-mimicking adhesives by using a 3,4-dihydroxstyrene monomer to mimic the DOPA side groups [79]. First protected by methyl groups, anionic polymerization initiated by $n$-butyl lithium successfully copolymerized styrene with this monomer to form a series of copolymers 
with different monomer feed ratios. Deprotection by boron tribromide released the hydroxyl groups, which were subjected to oxidation crosslinking. The authors tested and compared several different inorganic oxidative reagents, which might have limited medical applications due to toxicity. Recently, they also presented a systematic structureproperty relationship of the polystyrene-based sealant material [73].

In another study, Lee and Messersmith et al. synthesized a methacrylated dopamine monomer and applied free radical polymerization to generate DOPA-containing copolymers [80]. Inspired by the adhesion phenomena of both mussels and geckos, they designed a reversible wet/dry adhesive that allowed multiple reversible adhesion/detaching processes. A patterned polydimethylsiloxane (PDMS) substrate was created via electron beam lithography to mimic the structure of geckos, and the DOPAcontaining copolymer was spin-coated onto the substrate to incorporate the waterresistant adhesion properties [80].

Messersmith et al. also prepared DOPA-functionalized linear or multiple armed PEG to mimic mussel adhesive proteins [81-85]. When 4 armed DOPA-containing PEG was treated with different oxidative reagents, such as periodide, HRP, or mushroom tyrosinase, fast gelation was observed due to the crosslinking between the DOPA moieties or the coupling between oxidized DOPA and free amino groups [81]. In vivo performances of this DOPA-PEG sealant in extrahepatic islet transplantation was reported in a murine model [82]. Brubaker et al. later introduced an enzyme-degradable oligopeptide linkers between the PEG chains and the DOPA moieties, aiming to achieve regulated degradation of the hydrogels by enzyme. However, only relatively slow enzyme-catalyzed degradation behaviors were observed both in vitro and in vivo [83]. Recently, Barrett et al. further investigated how the crosslinking of DOPA-containing multiple armed PEG sealant could be influenced by the addition of $\mathrm{Fe}(\mathrm{III})$ ions and $\mathrm{pH}$ values of the solution, revealing significant $\mathrm{pH}$-regulated physical properties of the DOPA-PEG hydrogel system.

Similarly, the DOPA motif has also been introduced to other polymer systems, such as polyesters [86], polyallylamine [87], poly(ester amide)s [88, 89], poly(propylene oxide)-poly(ethylene oxide) block copolymers [85], and chitosan [57, 90]. DOPAcontaining sealants provide a promising candidate for various medical applications. 


\section{Applications of elastic surgical sealants}

According to the report from MedMarket Diligence, LLC, there are about 114 million procedure-based wounds to occur annually worldwide, among which 36 million cases are from surgeries in the US [91]. The market value for the surgical materials is expected to grow to \$4B in 2015 worldwide and may exceed \$7B in 2017 [92]. Although currently over two-thirds of the surgical product market is for hemostats, a greater sealant rate is expected due to the lack of suitable products. Surgical sealants are required to have high adhesion strength and proper function in wet environments. In addition, they must be flexible to move with the tissues. A high level of elasticity is particularly important for surgical procedures involving tissues that undergo continual expansion or contraction such as the heart, skin, blood vessels, and lungs. For example, in lung surgery the sealant might be applied when the lungs are deflated, therefore, the sealant is required to have elasticity similar to the lungs to support expansion and contraction of the tissue. In cardiovascular applications, the elasticity of the sealant plays a significant role in supporting proper expansion and contraction of the tissues during blood pumping.

In lung surgery, lung tissues must be sealed surgically via sutures, staples, or the implantation of surgical meshes. Despite their common use in the clinic, these mechanical methods are inevitably associated with lung tissue damage caused by deep piercing, ischemia, and prolonged air leaks, which represent the most common complications after lung surgeries [93]. Particularly, prolonged air leak could lead to extended chest tube drainage time that would increase the risk of developing infections and bronco-pleural fistulae in the patients, and consequently, a longer hospital stay with increased costs $[94,95]$.

A variety of complementary natural and synthetic materials have been applied to overcome such complications including fibrin sealants, collagen-based sealants, and synthetic glues [40, 96-101]. However, some of these surgical sealants lack appropriate elasticity, adhesion strength, and burst pressure required for sealing the lung tissues. In one study, a synthetic-based absorbable biomaterial called Focalseal consisting of a primer and a sealant solution was developed as a lung sealant $[14,15]$. The primer was first applied to the target tissue to wet the tissue for increasing adhesion. The PEG-based sealant solution was then injected and subsequently photopolymerized to seal the lung 
tissues. The results of in vivo test using a pig model showed no post-operation air leaks with intact bronchial closures. In their clinical study, it was found that $77 \%$ of treated patient with Focalseal remained leak free with no undesirable side effects [14]. However, its multiple steps application process due to the use of primer and light source for crosslinking makes its clinical applications challenging. In addition, it has been reported that Focalseal may potentially enhance the rate of post-operative empyema $[16,102]$. In another study, Kobayashi et al. developed an albumin-based hydrogel sealant, Progel, composed of two components including PEG disuccinimidyl succinate and human albumin, to stop air leaks in a rat lung model [50]. The sealing properties of the engineered lung sealant were compared to fibrin glue. The average burst pressure on day 3 of surgery was about $71 \mathrm{mmHg}$ for Progel, which was significantly higher than fibrin glue $(60 \mathrm{mmHg})$. In addition, no adverse tissue reaction was observed up to day 14 of operation [50]. The safety and effectiveness of Progel to stop air leaks after pulmonary surgery were also evaluated by testing the sealant on 161 patients [17]. Patient treated by Progel had less intra-operative and post-operative leakages and shorter hospitalization compared to the control group (65\% vs $86 \%$ and 6 day vs 7 days) [17]. This demonstrates the suitability of Progel in lung resection surgery for closing air leaks [4]. In another study, the burst pressure values for different lung sealants were compared in an ex vivo study using a porcine model [103]. Bioglue (V-Tech, Roskilde, Denmark) attained the highest burst pressures compared to other tested sealants including Evicel (OMRIX biopharmaceuticals S.A, Belgium), Tisseel (Baxter, Denmark), TachoSil (Nycomed, Roskilde, Denmark), TissuePatchDural (Vingmed, Denmark), and Pleuraseal (Covidien, Denmark). However, it was shown that the rigidity of the Bioglue caused lung tissue tearing and deformation [103]. Therefore, in addition to high burst pressure and adhesion strength, the flexibility of the lung sealants is an important parameter for their clinical applications.

In cardiovascular surgery, one of the main challenges is the inability to reconnect tissue or attach prosthetic materials in a wet and dynamic environment, such as continuous tissue contractions and blood flow. Most of currently available sealants have low adhesion strength and mechanical properties in wet conditions. To address this limitation, recently, an elastic blood-resistant light-activated tissue adhesive based on 
PGS has been developed for cardiovascular surgeries [5]. No inflammatory reaction was observed after applying the engineered glue on the rat heart, demonstrating its biocompatibility (Figure 5a). Successful closure of a transmural left ventricular wall defect in a rat model was also achieved (Figure 5b). In addition, the glue could effectively close defects in a pig carotid artery with no bleeding after $24 \mathrm{~h}$ of implantation (Figure 5c). An intact endothelium with no thrombus formation was observed by H\&E staining of the carotid arteries (Figure 5d) [5].

In another study, a photochemical tissue bonding technique (PTB) containing a photoactive dye with visible light was used for microvascular anastomosis [104]. The results of ex vivo test using porcine brachial arteries showed higher leak point pressure for PTB compared to suture (1100 $\mathrm{mmHg}$ vs $350 \mathrm{mmHg}$ ). In addition, no evidence of aneurysm formation was observed in PTB treated vessels without any bleeding, confirming the suitability of this technique for anastomosis as a sutureless alternative [104]. Similarly, Chang et al. developed and used a thermoresponsive poloxamer gel based on nanoparticles polyethylene oxide (PEO) and polypropylene oxide (PPO) for sutureless vascular anastomosis [105]. It was shown that the use of poloxamer gel for anastomosis significantly reduced inflammation and fibrosis for up to 2 years compared to hand-sewn anastomoses. Other advantages of this technique over standard suturebased vascular anastomosis include high speed and patency in small size vessels [105]. Vascular sealants have been also used in combination with sutures to control bleeding in vascular surgeries. For example, in one study, the hemostatic effectiveness of fibrin sealant in comparison with manual compression in a polytetrafluoroethylene (PTFE) arterial anastomosis was studies [106]. It was found that 85 percent of patients treated with fibrin sealant achieved hemostasis after 4 min as compared to 38 percent patients who were treated by manual compression [106]. In another study, the hemostatic properties of two vascular sealants including FloSeal (Fusion Medical Technology, Inc, CA) and Gelfoam-Thrombin (Gelfoam, Pharmacia and Upjohn, MI; Thrombin, Gentrac Inc, WI) were compared in a controlled clinical trial [107]. A total number of 93 patients were treated by FloSeal and Gelfoam-Thrombin after cardiac surgery. It was found that FloSeal matrix stopped bleeding in $94 \%$ of patients after $10 \mathrm{~min}$ as compared to $60 \%$ of patients treated by Gelfoam-Thrombin [107]. Similarly, Hewitt et al. investigated the use 
of Bioglue for thoracic aortic operation in a coagulopathic sheep model [108]. In their experiments, the sheep were first anticoagulated with heparin and then subjected to endto-side anastomoses of a graft to a thoracic aorta. The anastomoses were then treated by Bioglue and Surgicel (as control) to control bleeding. It was found that Bioglue significantly reduced the volume and rate of post-operation bleeding compared to control. However, a minimal inflammatory response was observed in the animals treated by Bioglue [108].

Polymer-based sealants have been also used to close skin wound defects. For example, in a recent study, a highly elastic and adhesive dendritic thioester hydrogel sealant was synthesized by forming of thioester linkages between the thiol residues of dendron and a PEG macromer [109]. The engineered sealant exhibited high mechanical properties and strong adhesion to the skin tissue even in the presence of torsion stress (Figure 6a). The sealant could also gradually dissolve after exposing to a thiolate solution due to a thiol-thioestyer exchange, allowing for controlled re-exposure of wound during surgical procedure. Similarly, Chen et al. fabricated a reinforced PEG/chitosan antibacterial hydrogel-based wound dressing to heal small and full-thickness defects in a mouse skin model [110]. An optimized ratio of PEG/chitosan could suppress inflammation, promote re-epithelialization and neo-vascularization, and prevent infection, demonstrating the suitability of the engineered hydrogel as a wound dressing adhesive [110]. In another study, an in situ curable PEG/chitosan-based tissue adhesive and hemostat was developed for wound closure [55]. The sealant was formed by grafting chitosan to PEG via enzymatic-mediated crosslinking using HRP and hydrogen peroxide. The resulting tissue adhesive had adhesion strength 20 -fold higher than fibrin glue as well as hemostatic ability to stop bleeding in the wound site. In addition, this tissue adhesive had higher healing power compared to suture, fibrin glue and cyanoacrylate after applying on the skin incision of rats [55]. The use of surgical adhesives for controlling wound drainage and seroma formation has been also studied [111]. For example, Walgenbach et al. used a lysine-based urethane adhesive TissuGlue to control drain time and volume in patients underwent abdominoplasty. It was found that TissueGlue significantly decreased the wound drainage and time required for postsurgical drains following abdominoplasty [111]. In a recent study, injectable citrate-based 
mussel-inspired tissue adhesives (iCMBAs) with high adhesion strength to wet surfaces were developed as sutureless wound closure bioadhesives (Figure 6b) [112]. The synthesized adhesive could close the wounds ( $2 \mathrm{~cm}$ long and $0.5 \mathrm{~cm}$ depth) created on the back of rats without the need for suturing, which was not possible by using standard fibrin glue adhesives (Figure 6c). It also facilitated wound healing process without causing inflammatory response (Figure 6d) [112].

\section{Conclusion and future directions}

The past several decades have witnessed the developments of tissue sealants based on synthetic and natural polymers. Characterizations on their physical and adhesive properties both in vitro and in vivo have demonstrated great potential to combine sealants with traditional tissue closure techniques in surgical operations. This is due to their advantages including easy application, strong adhesions and biodegradability. Many tissue sealants have received approval for clinical use and have been commercialized. Despite of the previous successful examples, there are still many challenges. Due to the variations of all kinds of different living tissues in human body, it is not practical to develop a universal tissue sealant that is suitable for all situations. Instead, properties of the tissue sealants should be carefully engineered and optimized by changing the chemical compositions, working reactions, and formulation of the adhesive materials for different applications. Highly elastic, biocompatible, and low cost sealants with superior mechanical and adhesive properties are still under developments.

It is also important to better understand the interactions between the adhesive biomaterials and the living tissues and the biological consequences after application of the sealants. Enhanced interactions of the implanted sealants with tissue interfaces could result in improved long term in vivo performance. Developing novel sealants that can not only physically join tissues together but also actively promote tissue growth and repair will also generate significant impact to current surgery procedures. It is anticipated that close collaboration between bioengineers, material scientists, and surgeons is required to efficiently advance the research of tissue sealants in future studies. 


\section{Acknowledgements}

N.A. acknowledges the support from the National Health and Medical Research Council.

The authors acknowledge funding from the National Science Foundation (EFRI1240443), IMMODGEL (602694), and the National Institutes of Health (EB012597, AR057837, DE021468, HL099073, AI105024, AR063745).

\section{References}

[1] N. Annabi, A. Tamayol, S.R. Shin, A.M. Ghaemmaghami, N.A. Peppas, A. Khademhosseini, Nano Today, 9 (2014) 574-589.

[2] L.W.S.S. MedMarket Diligence, Glues, Wound Closure and Anti-Adhesion Market, Forecast to 2017.

[3] Q. Chen, S. Liang, G.A. Thouas, Soft Matter, 7 (2011) 6484-6492.

[4] C. Fuller, Journal of cardiothoracic surgery, 8 (2013) 90.

[5] N. Lang, M.J. Pereira, Y. Lee, I. Friehs, N.V. Vasilyev, E.N. Feins, K. Ablasser, E.D. O'Cearbhaill, C. Xu, A. Fabozzo, R. Padera, S. Wasserman, F. Freudenthal, L.S. Ferreira, R. Langer, J.M. Karp, P.J. del Nido, Science Translational Medicine, 6 (2014) 218ra216.

[6] P. Ferreira, A.F.M. Silva, M.I. Pinto, M.H. Gil, Journal of Materials ScienceMaterials in Medicine, 19 (2008) 111-120.

[7] P. Ferreira, R. Pereira, J.F.J. Coelho, A.F.M. Silva, M.H. Gil, Int. J. Biol. Macromol., 40 (2007) 144-152.

[8] P. Ferreira, J.F.J. Coelho, M.H. Gil, Int. J. Pharm., 352 (2008) 172-181.

[9] T.W. Gilbert, S.F. Badylak, J. Gusenoff, E.J. Beckman, D.M. Clower, P. Daly, J.P. Rubin, Plastic and Reconstructive Surgery, 122 (2008) 95-102.

[10] K.D. Kim, N.M. Wright, Spine, 36 (2011) 1906-1912.

[11] P. Fransen, Spine Journal, 10 (2010) 751-761.

[12] G. Lee, C.K. Lee, M. Bynevelt, Spine, 35 (2010) E1522-E1524.

[13] M.C. Preul, W.D. Bichard, T.R. Muench, R.F. Spetzler, Neurosurgery, 53 (2003) 1189-1199.

[14] P. Macchiarini, J. Wain, S. Almy, P. Dartevelle, The Journal of Thoracic and Cardiovascular Surgery, 117 (1999) 751-758.

[15] A.M. Gillinov, B.W. Lytle, Journal of Cardiac Surgery, 16 (2001) 255-257.

[16] J.C. Wain, L.R. Kaiser, D.W. Johnstone, S.C. Yang, C.D. Wright, J.S. Friedberg, R.H. Feins, R.F. Heitmiller, D.J. Mathisen, M.R. Selwyn, Annals of Thoracic Surgery, 71 (2001) 1623-1629.

[17] M.S. Allen, D.E. Wood, R.W. Hawkinson, D.H. Harpole, R.J. McKenna, G.L. Walsh, E. Vallieres, D.L. Miller, F.C. Nichols, W.R. Smythe, R.D. Davis, M.T.M.S.S.S. Grp, Annals of Thoracic Surgery, 77 (2004) 1792-1801.

[18] D.G. Wallace, G.M. Cruise, W.M. Rhee, J.A. Schroeder, J.J. Prior, J. Ju, M. Maroney, J. Duronio, M.H. Ngo, T. Estridge, G.C. Coker, Journal of Biomedical Materials Research, 58 (2001) 545-555. 
[19] A. Hill, T.D. Estridge, M. Maroney, E. Monnet, B. Egbert, G. Cruise, G.T. Coker, Journal of Biomedical Materials Research, 58 (2001) 308-312.

[20] J.C. Wheat, J.S. Wolf Jr, Urologic Clinics of North America, 36 (2009) 265-275.

[21] C.L.E. Nijst, J.P. Bruggeman, J.M. Karp, L. Ferreira, A. Zumbuehl, C.J. Bettinger, R. Langer, Biomacromolecules, 8 (2007) 3067-3073.

[22] N. Lang, M.J. Pereira, Y. Lee, I. Friehs, N.V. Vasilyev, E.N. Feins, K. Ablasser, E.D. O'Cearbhaill, C. Xu, A. Fabozzo, R. Padera, S. Wasserman, F. Freudenthal, L.S. Ferreira, R. Langer, J.M. Karp, P.J. del Nido, Sci Transl Med, 6 (2014) 218ra216.

[23] S. Sakai, M. Tsumura, M. Inoue, Y. Koga, K. Fukano, M. Taya, Journal of Materials Chemistry B, 1 (2013) 5067-5075.

[24] M.R. Jackson, The American Journal of Surgery, 182 (2001) S1-S7.

[25] B.M. Alving, M.J. Weinstein, J.S. Finlayson, J.E. Menitove, J.C. Fratantoni, Transfusion, 35 (1995) 783-790.

[26] U. Martinowitz, R. Saltz, Current opinion in hematology, 3 (1996) 395-402.

[27] R.W. Busuttil, Journal of the American College of Surgeons, 197 (2003) 10211028.

[28] A.P. Duarte, J.F. Coelho, J.C. Bordado, M.T. Cidade, M.H. Gil, Prog. Polym. Sci., 37 (2012) 1031-1050.

[29] S.P. Mandell, N.S. Gibran, Expert Opinion on Biological Therapy, 14 (2014) 821830.

[30] D.A. Fancy, T. Kodadek, Proc. Natl. Acad. Sci., 96 (1999) 6020-6024.

[31] C.M. Elvin, A.G. Carr, M.G. Huson, J.M. Maxwell, R.D. Pearson, T. Vuocolo, N.E. Liyou, D.C.C. Wong, D.J. Merritt, N.E. Dixon, Nature, 437 (2005) 999-1002.

[32] C.M. Elvin, A.G. Brownlee, M.G. Huson, T.A. Tebb, M. Kim, R.E. Lyons, T. Vuocolo, N.E. Liyou, T.C. Hughes, J.A.M. Ramshaw, J.A. Werkmeister, Biomaterials, 30 (2009) 2059-2065.

[33] C.M. Elvin, S.J. Danon, A.G. Brownlee, J.F. White, M. Hickey, N.E. Liyou, G.A. Edwards, J.A.M. Ramshaw, J.A. Werkmeister, Journal of Biomedical Materials Research Part A, 93A (2010) 687-695.

[34] C.M. Elvin, T. Vuocolo, A.G. Brownlee, L. Sando, M.G. Huson, N.E. Liyou, P.R. Stockwell, R.E. Lyons, M. Kim, G.A. Edwards, G. Johnson, G.A. McFarland, J.A.M. Ramshaw, J.A. Werkmeister, Biomaterials, 31 (2010) 8323-8331.

[35] T. Vuocolo, R. Haddad, G.A. Edwards, R.E. Lyons, N.E. Liyou, J.A. Werkmeister, J.A.M. Ramshaw, C.M. Elvin, Journal of Gastrointestinal Surgery, 16 (2012) 744-752.

[36] N. Annabi, A. Tamayol, J.A. Uquillas, M. Akbari, L.E. Bertassoni, C. Cha, G. CamciUnal, M.R. Dokmeci, N.A. Peppas, A. Khademhosseini, Advanced Materials, 26 (2014) 85-124.

[37] M. Hino, O. Ishiko, K.I. Honda, T. Yamane, K. Ohta, T. Takubo, N. Tatsumi, British journal of haematology, 108 (2000) 194-195.

[38] R.F. Nistor, F.M. Chiari, H. Maier, K. Hehl, Skull Base Surgery, 7 (1997) 23-30.

[39] J.M. Albes, C. Krettek, B. Hausen, R. Rohde, A. Haverich, H.G. Borst, C.J. Tatooles, Annals of Thoracic Surgery, 56 (1993) 910-915.

[40] H. Nomori, H. Horio, S. Morinaga, K. Suemasu, Annals of Thoracic Surgery, 67 (1999) 212-216.

[41] H. Nomori, T. Horio, K. Suemasu, Surgery Today-the Japanese Journal of Surgery, 30 (2000) 244-248. 
[42] H. Iwata, S. Matsuda, K. Mitsuhashi, E. Itoh, Y. Ikada, Biomaterials, 19 (1998) 1869-1876.

[43] M. Matsuda, M. Inoue, T. Taguchi, Journal of Bioactive and Compatible Polymers, 27 (2012) 481-498.

[44] M. Matsuda, M. Ueno, Y. Endo, M. Inoue, M. Sasaki, T. Taguchi, Colloids and Surfaces B-Biointerfaces, 91 (2012) 48-56.

[45] Y. Nakayama, T. Matsuda, Journal of Biomedical Materials Research, 48 (1999) 511-521.

[46] T.H. Chen, H.D. Embree, E.M. Brown, M.M. Taylor, G.F. Payne, Biomaterials, 24 (2003) 2831-2841.

[47] M.K. McDermott, T.H. Chen, C.M. Williams, K.M. Markley, G.F. Payne, Biomacromolecules, 5 (2004) 1270-1279.

[48] T.H. Chen, R. Janjua, M.K. McDermott, S.L. Bernstein, S.M. Steidl, G.F. Payne, Journal of Biomedical Materials Research Part B-Applied Biomaterials, 77B (2006) 416-422.

[49] H.-H. Chao, D.F. Torchiana, Journal of Cardiac Surgery, 18 (2003) 500-503.

[50] H. Kobayashi, T. Sekine, T. Nakamura, Y. Shimizu, Journal of Biomedical Materials Research, 58 (2001) 658-665.

[51] K. Ono, Y. Saito, H. Yura, K. Ishikawa, A. Kurita, T. Akaike, M. Ishihara, Journal of Biomedical Materials Research, 49 (2000) 289-295.

[52] M. Ishihara, Trends in Glycoscience and Glycotechnology, 14 (2002) 331-341.

[53] M. Ishihara, K. Nakanishi, K. Ono, M. Sato, M. Kikuchi, Y. Saito, H. Yura, T. Matsui, H. Hattori, M. Uenoyama, A. Kurita, Biomaterials, 23 (2002) 833-840.

[54] G. Liu, Z. Shi, T. Kuriger, L.R. Hanton, J. Simpson, S.C. Moratti, B.H. Robinson, T. Athanasiadis, R. Valentine, P.J. Wormald, S. Robinson, Macromolecular Symposia, 279 (2009) 151-157.

[55] E. Lih, J.S. Lee, K.M. Park, K.D. Park, Acta Biomaterialia, 8 (2012) 3261-3269.

[56] W. Nie, X. Yuan, J. Zhao, Y. Zhou, H. Bao, Carbohydr. Polym., 96 (2013) 342-348.

[57] J.H. Ryu, Y. Lee, M.J. Do, S.D. Jo, J.S. Kim, B.-S. Kim, G.-I. Im, T.G. Park, H. Lee, Acta Biomaterialia, 10 (2014) 224-233.

[58] C. Hiemstra, L.J. van der Aa, Z. Zhong, P.J. Dijkstra, J. Feijen, Macromolecules, 40 (2007) 1165-1173.

[59] R. Jin, C. Hiemstra, Z. Zhong, J. Feijen, Biomaterials, 28 (2007) 2791-2800.

[60] M. Araki, H. Tao, N. Nakajima, H. Sugai, T. Sato, S.-H. Hyon, T. Nagayasu, T. Nakamura, Journal of Thoracic and Cardiovascular Surgery, 134 (2007) 1241-1248.

[61] M. Araki, H. Tao, T. Sato, N. Nakajima, H. Sugai, S.-H. Hyon, T. Nagayasu, T. Nakamura, Journal of Thoracic and Cardiovascular Surgery, 134 (2007) 145-151.

[62] S.K. Bhatia, S.D. Arthur, H.K. Chenault, G.K. Kodokian, Biotechnol. Lett, 29 (2007) 1645-1649.

[63] Q. Li, C.G. Williams, D.D.N. Sun, J. Wang, K. Leong, J.H. Elisseeff, Journal of Biomedical Materials Research Part A, 68A (2004) 28-33.

[64] J.M.G. Reyes, S. Herretes, A. Pirouzmanesh, D.A. Wang, J.H. Elisseeff, A. Jun, P.J. McDonnell, R.S. Chuck, A. Behrens, Investigative Ophthalmology \& Visual Science, 46 (2005) 1247-1250.

[65] D.-A. Wang, S. Varghese, B. Sharma, I. Strehin, S. Fermanian, J. Gorham, D.H. Fairbrother, B. Cascio, J.H. Elisseeff, Nature Mater., 6 (2007) 385-392. 
[66] I. Strehin, W.M. Ambrose, 0. Schein, A. Salahuddin, J. Elisseeff, Journal of Cataract and Refractive Surgery, 35 (2009) 567-576.

[67] I. Strehin, Z. Nahas, K. Arora, T. Nguyen, J. Elisseeff, Biomaterials, 31 (2010) 2788-2797.

[68] J.H. Waite, Int. J. Adhes. Adhes., 7 (1987) 9-14.

[69] V. Vreeland, J.H. Waite, L. Epstein, Journal of Phycology, 34 (1998) 1-8.

[70] H. Tatehata, A. Mochizuki, T. Kawashima, S. Yamashita, H. Yamamoto, J. Appl.

Polym. Sci., 76 (2000) 929-937.

[71] J.H. Waite, J. Biol. Chem., 258 (1983) 2911-2915.

[72] M. Yu, J. Hwang, T.J. Deming, J. Am. Chem. Soc., 121 (1999) 5825-5826.

[73] C.R. Matos-Perez, J.D. White, J.J. Wilker, J. Am. Chem. Soc., 134 (2012) 94989505.

[74] D.J. Crisp, G. Walker, G.A. Young, A.B. Yule, Journal of Colloid and Interface Science, 104 (1985) 40-50.

[75] M.E. Yu, T.J. Deming, Macromolecules, 31 (1998) 4739-4745.

[76] D.S. Hwang, Y. Gim, H.J. Yoo, H.J. Cha, Biomaterials, 28 (2007) 3560-3568.

[77] A. Salerno, I. Goldberg, Appl. Microbiol. Biotechnol., 39 (1993) 221-226.

[78] J. Wang, C. Liu, X. Lu, M. Yin, Biomaterials, 28 (2007) 3456-3468.

[79] G. Westwood, T.N. Horton, J.J. Wilker, Macromolecules, 40 (2007) 3960-3964.

[80] H. Lee, B.P. Lee, P.B. Messersmith, Nature, 448 (2007) 338-U334.

[81] B.P. Lee, J.L. Dalsin, P.B. Messersmith, Biomacromolecules, 3 (2002) 1038-1047.

[82] C.E. Brubaker, H. Kissler, L.-J. Wang, D.B. Kaufman, P.B. Messersmith, Biomaterials, 31 (2010) 420-427.

[83] C.E. Brubaker, P.B. Messersmith, Biomacromolecules, 12 (2011) 4326-4334.

[84] D.G. Barrett, D.E. Fullenkamp, L. He, N. Holten-Andersen, K.Y.C. Lee, P.B. Messersmith, Adv. Funct. Mater., 23 (2013) 1111-1119.

[85] D.G. Barrett, G.G. Bushnell, P.B. Messersmith, Advanced Healthcare Materials, 2 (2013) 745-755.

[86] J.L. Murphy, L. Vollenweider, F. Xu, B.P. Lee, Biomacromolecules, 11 (2010) 2976-2984.

[87] M. Krogsgaard, M.A. Behrens, J.S. Pedersen, H. Birkedal, Biomacromolecules, 14 (2013) 297-301.

[88] I. Manolakis, B.A.J. Noordover, R. Vendamme, W. Eevers, Macromol. Rapid Commun., 35 (2014) 71-76.

[89] H. Zhang, L.P. Bré, T. Zhao, Y. Zheng, B. Newland, W. Wang, Biomaterials, 35 (2014) 711-719.

[90] J.H. Ryu, Y. Lee, W.H. Kong, T.G. Kim, T.G. Park, H. Lee, Biomacromolecules, 12 (2011) 2653-2659.

[91] L. MedMarket Diligence, Report \#S190, Worldwide Surgical Sealants, Glues, Wound Closure and Anti-Adhesion Markets, 2010-2017

[92] L.R.S. MedMarket Diligence, Worldwide Surgical Sealants, Glues, Wound Closure and Anti-Adhesion Markets, 2008-2015

[93] A. Belboul, L. Dernevik, O. Aljassim, B. Skrbic, G. Radberg, D. Roberts, Eur J Cardiothorac Surg, 26 (2004) 1187-1191.

[94] A. D'Andrilli, C. Andreetti, M. Ibrahim, A.M. Ciccone, F. Venuta, U. Mansmann, E.A. Rendina, Eur J Cardiothorac Surg, 35 (2009) 817-820; discussion 820-811. 
[95] L. Bertolaccini, P. Lyberis, E. Manno, J Cardiothorac Surg, 5 (2010) 45.

[96] A. Brunelli, M. Monteverde, A. Borri, M. Salati, R.D. Marasco, A. Fianchini, The Annals of thoracic surgery, 77 (2004) 1205-1210; discussion 1210.

[97] T. Fabian, J.A. Federico, R.B. Ponn, Annals of Thoracic Surgery, 75 (2003) 15871592.

[98] G. Cardillo, F. Carleo, L. Carbone, A.R. De Massimi, A. Lococo, P.F. Santini, A. Janni, A. Gonfiotti, European Journal of Cardio-Thoracic Surgery, 41 (2012) 657-662. [99] A. Gonfiotti, P.F. Santini, M. Jaus, A.J. Phd, A. Lococo, A.R. De Massimi, A. D'Agostino, F. Carleo, M. Di Martino, V. Larocca, G. Cardillo, Annals of Thoracic Surgery, 92 (2011) 1217-1224.

[100] C. Moser, I. Opitz, W. Zhai, V. Rousson, E.W. Russi, W. Weder, D. Lardinois, Journal of Thoracic and Cardiovascular Surgery, 136 (2008) 843-849.

[101] U. Anegg, V. Matzi, J. Smolle, A. Maier, F. Smolle-Juettner, European Journal of Cardio-Thoracic Surgery, 31 (2007) 198-202.

[102] H.L. Porte, T. Jany, R. Akkad, M. Conti, P.A. Gillet, A. Guidat, A.J. Wurtz, Annals of Thoracic Surgery, 71 (2001) 1618-1622.

[103] T.B. Pedersen, J.L. Honge, H.K. Pilegaard, J.M. Hasenkam, Annals of Thoracic Surgery, 94 (2012) 234-240.

[104] A.C. O'Neill, J.M. Winograd, J.L. Zeballos, T.S. Johnson, M.A. Randolph, K.E. Bujold, I.E. Kochevar, R.W. Redmond, Lasers in Surgery and Medicine, 39 (2007) 716-722.

[105] E.I. Chang, M.G. Galvez, J.P. Glotzbach, C.D. Hamou, S. El-ftesi, C.T. Rappleye, K.M. Sommer, J. Rajadas, O.J. Abilez, G.G. Fuller, M.T. Longaker, G.C. Gurtner, Nature Medicine, 17 (2011) 1147-U1160.

[106] R.T. Chalmers, R.C. Darling Iii, J.T. Wingard, I. Chetter, B. Cutler, J.A. Kern, J.C. Hart, Br J Surg, 97 (2010) 1784-1789.

[107] M.C. Oz, D.M. Cosgrove, B.R. Badduke, J.D. Hill, M.R. Flannery, R. Palumbo, N. Topic, G. Fusion Matrix Study, Annals of Thoracic Surgery, 69 (2000) 1376-1382.

[108] C.W. Hewitt, S.W. Marra, B.R. Kann, H.S. Tran, M.M. Puc, F.A. Chrzanowski, Jr., J.L. Tran, S.D. Lenz, J.H. Cilley, Jr., V.A. Simonetti, A.J. DelRossi, Ann Thorac Surg, 71 (2001) 1609-1612.

[109] C. Ghobril, K. Charoen, E.K. Rodriguez, A. Nazarian, M.W. Grinstaff, Angew. Chem. Int. Ed., 52 (2013) 14070-14074.

[110] S.-H. Chen, C.-T. Tsao, C.-H. Chang, Y.-T. Lai, M.-F. Wu, C.-N. Chuang, H.-C. Chou, C.-K. Wang, K.-H. Hsieh, Materials Science and Engineering: C, 33 (2013) 2584-2594.

[111] K.J. Walgenbach, H. Bannasch, S. Kalthoff, J.P. Rubin, Aesthetic Plastic Surgery, 36 (2012) 491-496.

[112] M. Mehdizadeh, H. Weng, D. Gyawali, L. Tang, J. Yang, Biomaterials, 33 (2012) 7972-7983.

[113] M. Mehdizadeh, J. Yang, Macromolecular Bioscience, 13 (2013) 271-288. 


\section{FIGURES}

(a)

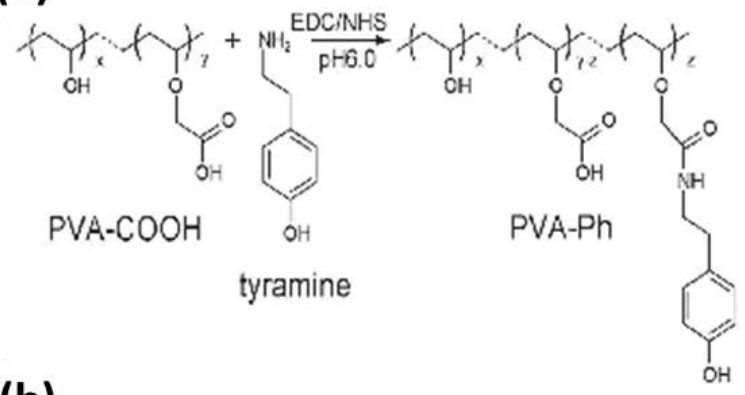

(b)

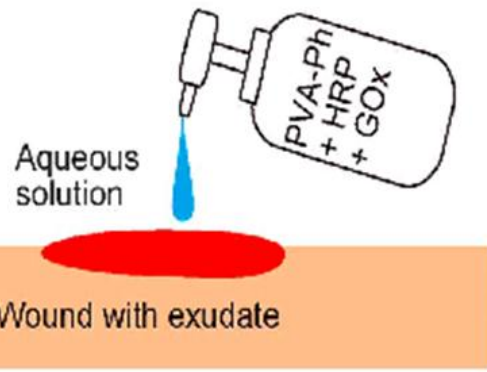

(c)

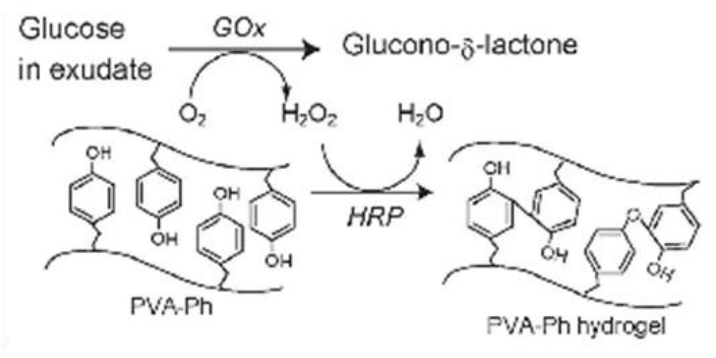

(d)

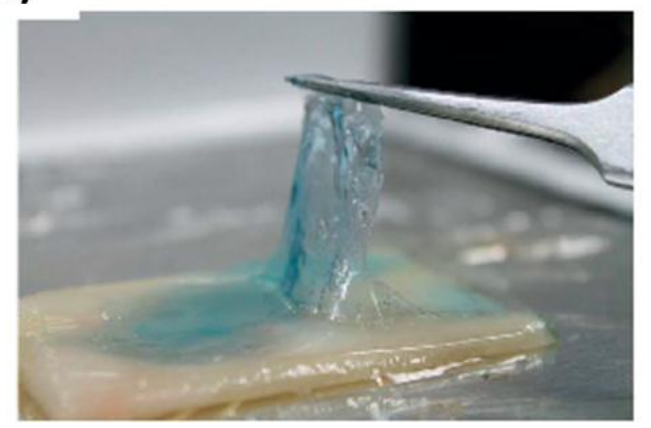

Figure 1. Elastic PVA-based bioadhesives. (a) Synthesis of PVA-Ph. (b) Wound was treated by applying the pre-hydrogel solution. (c) Formation of PVA-based hydrogel was achieved via the reactions catalyzed by GOx and HRP with the presence of glucose in the exudate. (d) PVA-based adhesive formed onto a cellulose dialysis membrane. Adapted from Ref [23] with permission from The Royal Society of Chemistry, copyright 2013. 
(a)
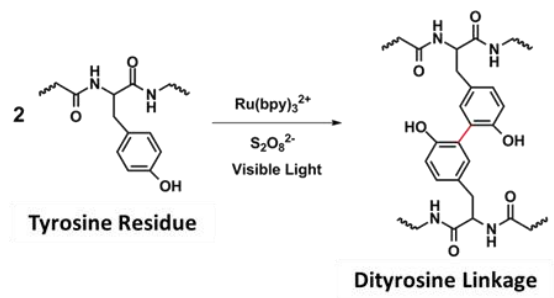

(c)

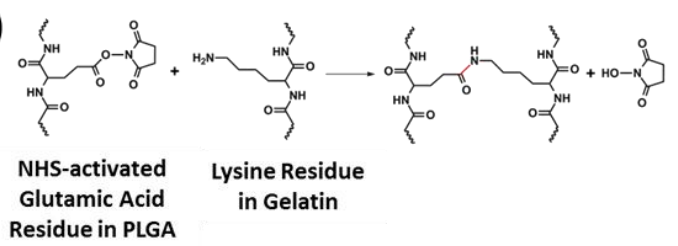

(d)

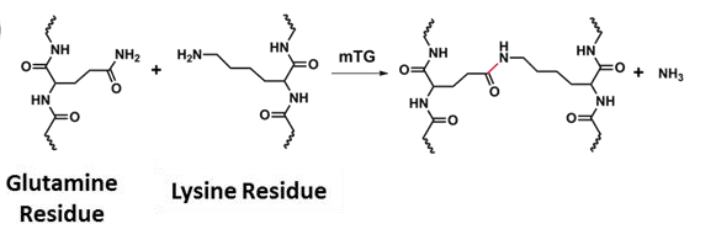

(b)

(i)

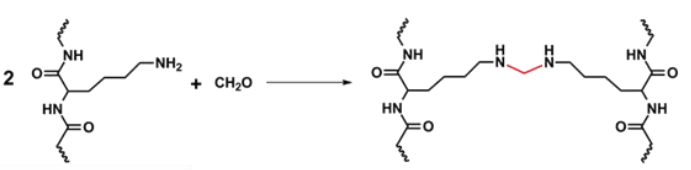

Lysine Residue

(ii)

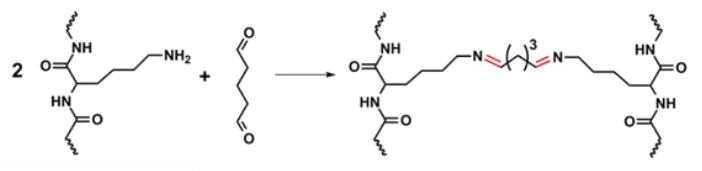

Lysine Residue

(iii)

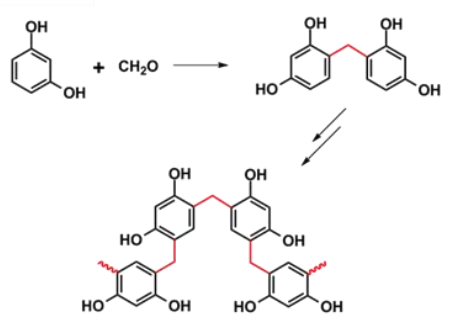

Figure 2. Typical reactions used for crosslinking in polypeptide/protein-based sealants. (A) Ru-catalyzed visible light promoted reaction to chemically crosslink tyrosinecontaining proteins and polypeptides via the formation of dityrosine linkages [30]. (B) Crosslinking mechanism of GRF or GRFG sealants, including (i) the reaction between lysine residues and formaldehyde, (ii) Schiff base formation between lysine residues and glutaraldehyde, and (iii) formation of the network structure from formaldehyde and resorcinol [39-41]. (C) Reaction between NHS-activated poly(L-glutamic acid) and gelatin [42]. (D) Reaction between the glutamine residue and lysine residue catalyzed by mTG [46]. 
(a)

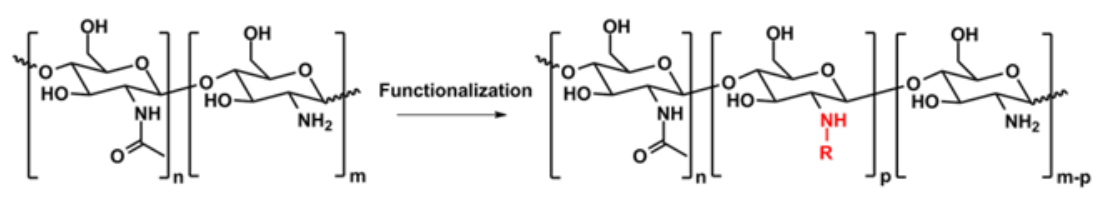

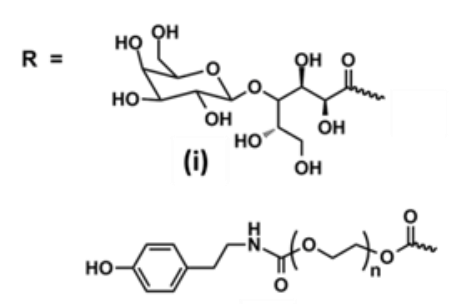

(iv)

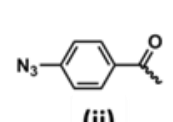

(ii)

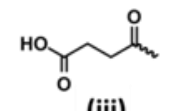

(iii)

(b)<smiles>CC(=O)CCCCCCC(C)=O</smiles>

(v)

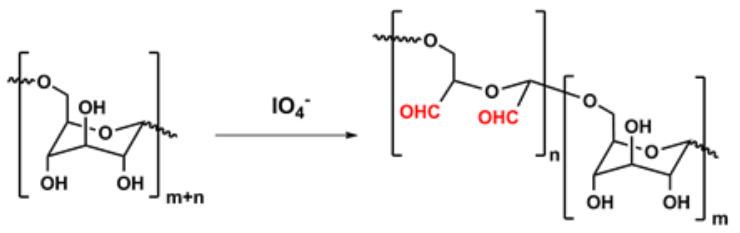

(c)

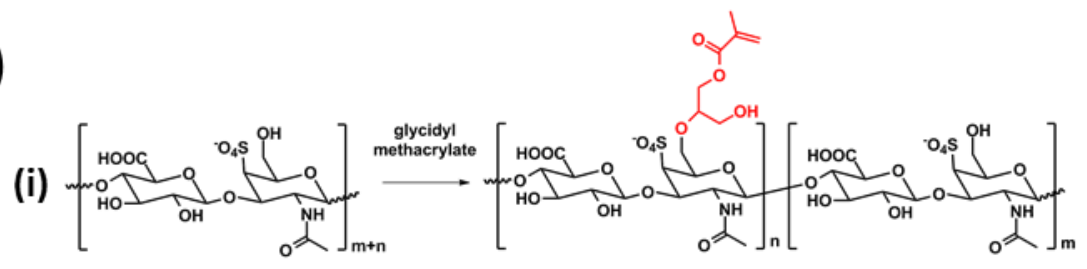

(ii)
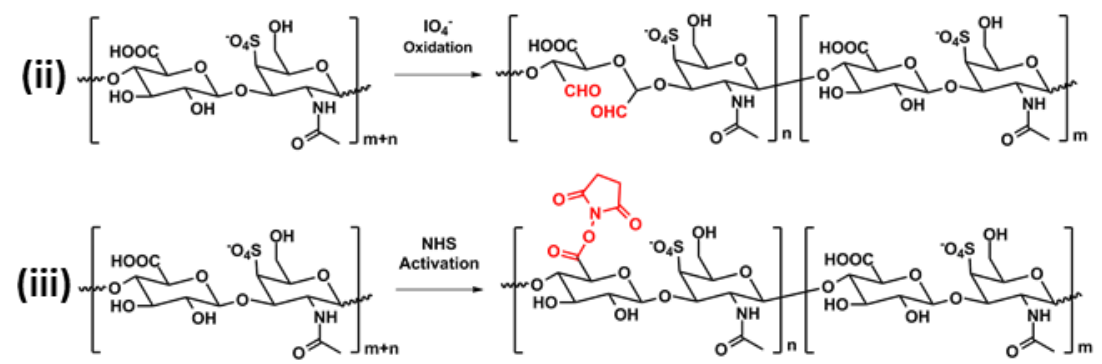

Figure 3. Representative chemical structures of polysaccharide-based sealants. (A) Deacetylation of chitin generates chitosan with different degrees of acetylation, and various chemically modified chitosan derivatives are obtained by reacting chitosan with (i) lactobionic acid, (ii) 4-azidobenzoic acid, (iii) succinic anhydride, (iv) PEG oligomers, (v) $\mathrm{N}$-acetylcysteine, and (vi) 3-mercaptopropionic acid at the amine site [51-57]. (B) Preparation of aldehyde-containing dextran via selective partial oxidation by periodide [60, 61]. (C) Chemical modification of chondroitin sulfate to introduce (i) methacrylate groups via reacting with glycidyl methacrylate [63], (ii) aldehyde groups via the oxidation reaction by periodide [64], and (iii) NHS-activated ester groups [66]. 

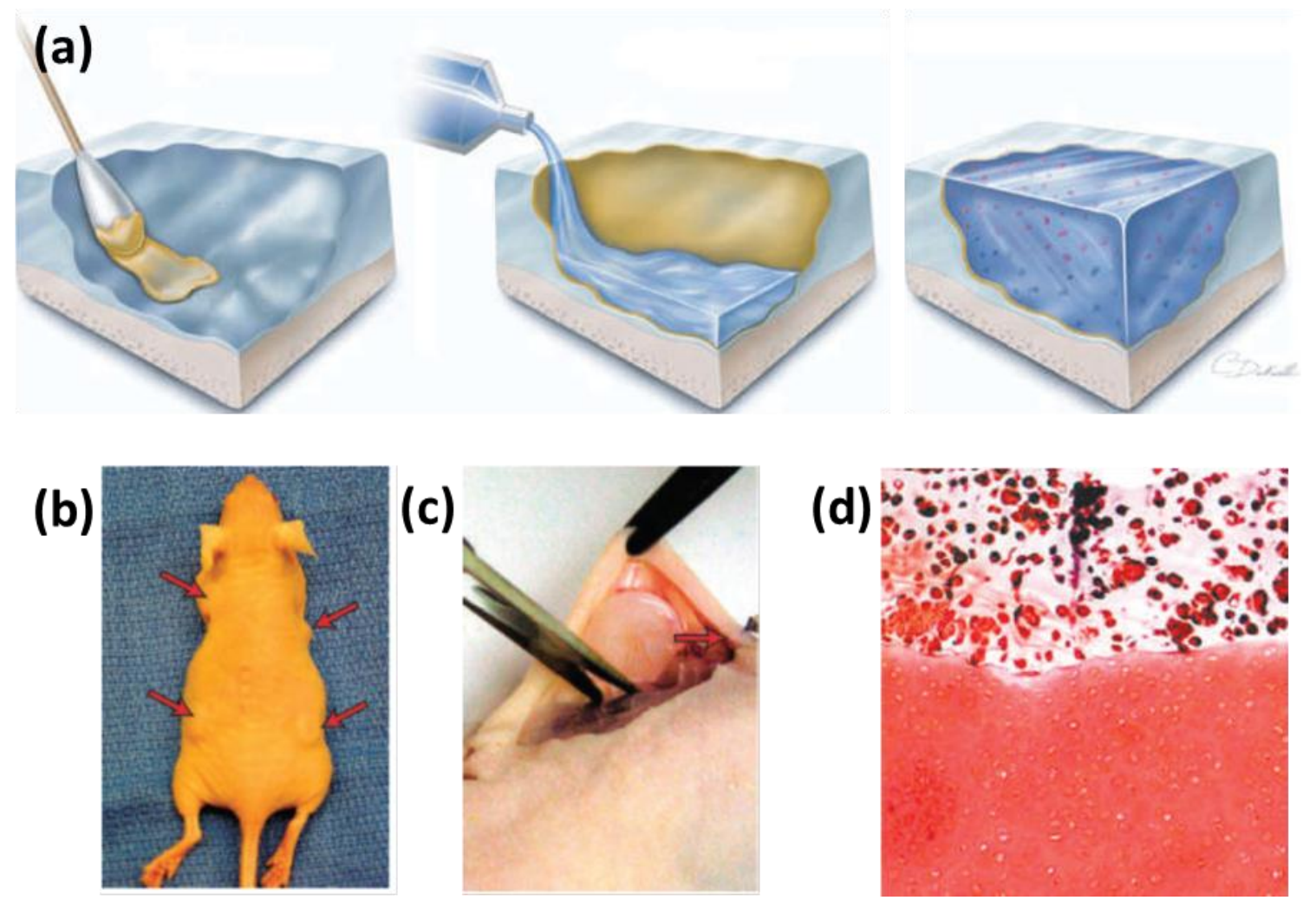

Figure 4. (A) Schematic diagram showing application of the chondroitin sulfate-based adhesive for hydrogel-tissue integration. The yellow colored layer indicated the chondroitin sulfate layer which served as the bridge between the cartilage tissue and the hydrogel. (B) In vivo subcutaneous implantation of the integrated cartilage-hydrogel constructs in a mice model. (C) Sample explantation after 5 weeks. (D) Safranin-O was found throughout the hydrogel layer and at the interface between the engineered and native cartilage tissues. Adapted from Ref [66] with permission from Nature Publishing Group, copyright 2007. 
(a)

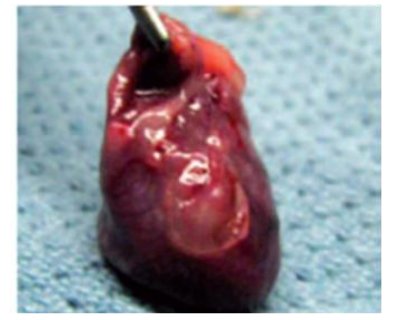

(c)

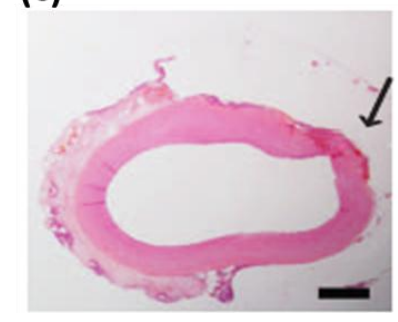

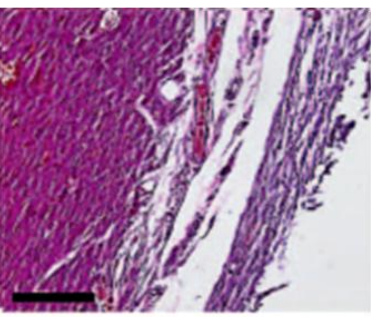

(d)

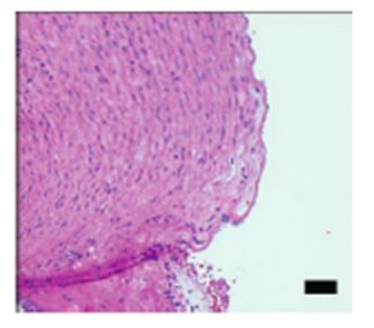

(b)
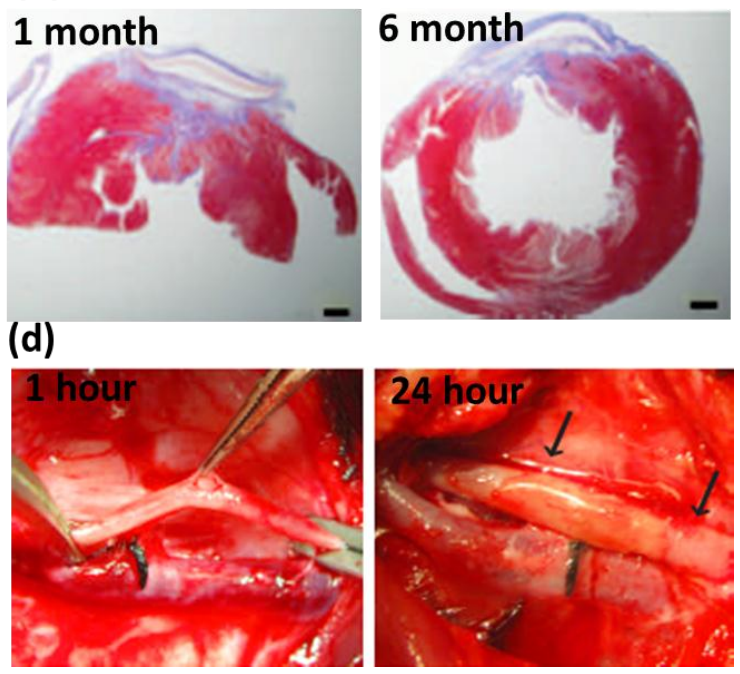

Figure 5. Highly elastic PGS-based glue for cardiovascular surgeries. (a) Explanted rat heart treated by the engineered glue after 14 days and corresponding $\mathrm{H} \& \mathrm{E}$ staining of the tissue in contact with the glue. (b) H\&E and MT staining of the rat cardiac tissue after 1 and 6 months of defect closure with the glue, showing the formation of scarring and accumulation of organized collagen (scale bars: $1 \mathrm{~mm}$ ). (c) H\&E staining of Pig carotid artery after treating with glue (scale bars: $1 \mathrm{~mm}$ (left) and $50 \mu \mathrm{m}$ (right). The arrow points to the defect created. (d) Pig carotid artery one hour after incision creation and 24 hours after closure with HLAA. No bleeding was detected at the defects after $24 \mathrm{~h}$ of operation, as indicated by arrows. Adapted from Ref [5] with permission from the AAAS, copyright 2014. 


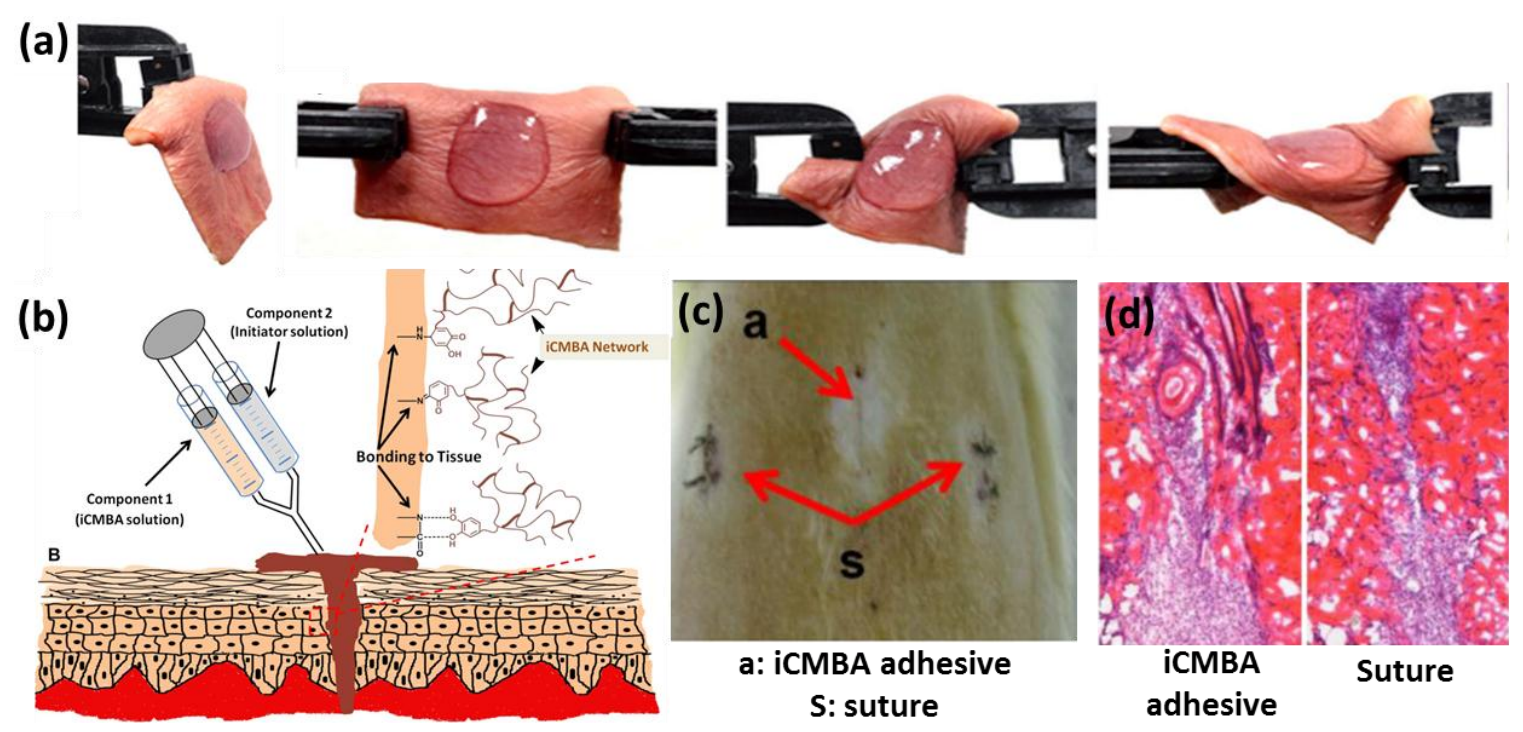

Figure 6. Surgical sealants as skin wound closures. (a) Photographs of a dendritic thioester hydrogel adhered to human skin under torsion. (b-c) an injectable iCMBA adhesive for sutureless wound closure; (b) schematic of iCMBA adhesive for wound closure, (c) images from dorsum skin treated by the adhesive and suture 7 days post operation, which shows that the wounds were closed by both methods (red arrows), and (d) H\&E images of wounds closed by iCMBA adhesives and suture at day 7 post treatment. Panels a, c, and d are adapted from Ref [112] with permission from Elsevier, copyright 2012; panel b is adapted from Ref [113] with permission from Wiley, copyright 2013. 


\section{TABLE}

Table 1. Summary of the representative surgical sealants.

\begin{tabular}{|c|c|c|c|}
\hline Base materials & Applications & Components and products & References \\
\hline Polyurethane & $\begin{array}{l}\text { - Fixation of vascular graft and } \\
\text { bone } \\
\text { - Abdominoplasty surgery to } \\
\text { avoid seroma formation }\end{array}$ & $\begin{array}{l}\text { - Engineered polyurethane with low } \\
\text { haemolytic responses } \\
\text { - Lysine-based, spayable urethane adhesive } \\
\text { (TissuGlu) }\end{array}$ & {$[6-8]$} \\
\hline PEG & $\begin{array}{l}\text { - Prevent cerebrospinal fluid } \\
\text { leakage after cranial operations } \\
\text { and reduce scar tissue and pain } \\
\text { after lumbar microdiscectomy } \\
\text { - Stop air leaks after lung } \\
\text { surgeries } \\
\text { - Seal suture lines and stop } \\
\text { bleeding in vascular surgeries }\end{array}$ & $\begin{array}{l}\text { - Tetra-succinimidyl PEG and tri-lysine } \\
\text { amine (DuraSeal) } \\
\text { - Acrylated PEG, polyester primer, and } \\
\text { photoinitiator (FocalSeal) } \\
\text { - Glutaryl-succinimidyl ester and thiol } \\
\text { terminated PEG (Coseal) }\end{array}$ & $\begin{array}{l}{[10-13]} \\
{[14-16]} \\
{[18,19]}\end{array}$ \\
\hline Polyester & $\begin{array}{l}\text { - Reduce the incidence of fluidic } \\
\text { or air leaks } \\
\text { - Repair of vessels and heart } \\
\text { defects }\end{array}$ & $\begin{array}{l}\text { - Poly(glycerol sebacate) (PGS) } \\
\text { - Photocrosslinkable PGS derivatives }\end{array}$ & $\begin{array}{c}{[3,21,22]} \\
{[5]}\end{array}$ \\
\hline $\begin{array}{l}\text { Polyvinyl } \\
\text { alcohol }\end{array}$ & - Close wound in surgery & - Tyramine-modified PVA & {$[23]$} \\
\hline Fibrin & $\begin{array}{l}\text { - Haemorrhage control, wound } \\
\text { closure and tissue anastomoses }\end{array}$ & $\begin{array}{l}\text { - Fibrinogen and thrombin (Tisseel, Evicel, } \\
\text { Crosseal, Hemaseel, etc.) } \\
\text { - Fibrinogen and a ruthenium photo- } \\
\text { catalyst }\end{array}$ & $\begin{array}{l}{[24-29,106]} \\
{[30,32,33]}\end{array}$ \\
\hline Collagen & - Haemostasis & - Bovine collagen and thrombin & [37] \\
\hline Gelatin & $\begin{array}{l}\text { - Thoracic aortic dissections and } \\
\text { hemostasis } \\
\text { - Seal surgical incisions in } \\
\text { gastrointestinal tract surgeries } \\
\text { - Repair retinal tissues }\end{array}$ & $\begin{array}{l}\text { - Gelatin-resorcinol-formaldehyde- } \\
\text { glutaraldehye } \\
\text { - Gelatin and } N \text {-hydroxysuccinimide-ester } \\
\text { functionalized poly(L-glutamic acid) or } \\
\text { disuccinimidyl tartrate } \\
\text { - Photocrosslinkable gelatin adhesives } \\
\text { - Gelatin and microbial transglutaminase }\end{array}$ & $\begin{array}{c}{[39-41]} \\
{[42-44]} \\
{[34,35,45]} \\
{[46-48]} \\
\end{array}$ \\
\hline Albumin & $\begin{array}{l}\text { - Hemostats in vascular and } \\
\text { cardiac surgeries } \\
\text { - Prevent air leakage in lung } \\
\text { surgeries }\end{array}$ & $\begin{array}{l}\text { - Bovine albumin and glutaraldehyde } \\
\text { (Bioglue) } \\
\text { - Human albumin and a NHS-activated } \\
\text { PEG (Progel) }\end{array}$ & $\begin{array}{l}{[49,108]} \\
{[4,50]}\end{array}$ \\
\hline Chitosan & - Wound closure and hemostasis & $\begin{array}{l}\text { - Lactobionic acid and azide functionalized } \\
\text { chitosan } \\
\text { - Tyrosine-modified chitosan, HPR and } \\
\text { hydrogen peroxide } \\
\text { - Thiol-containing chitosan and maleimide } \\
\text { containing } \varepsilon \text {-polylysine }\end{array}$ & $\begin{array}{c}{[51-53]} \\
{[55]}\end{array}$ \\
\hline Dextran & $\begin{array}{l}\text { - Stop air leaks after lung } \\
\text { surgeries }\end{array}$ & $\begin{array}{l}\text { - Aldehyde-containing dextran and amine- } \\
\text { containing PEG or polylysine crosslinkers }\end{array}$ & {$[58-62]$} \\
\hline $\begin{array}{l}\text { Chondroitin } \\
\text { sulfate }\end{array}$ & $\begin{array}{l}\text { - Seal corneal incisions } \\
\text { - Binding to native cartilage } \\
\text { tissue } \\
\text { - Wound closure }\end{array}$ & $\begin{array}{l}\text { - Aldehyde-bearing chondroitin sulfate and } \\
\text { poly(vinyl alcohol-co-vinyl amine) } \\
\text { - Methacrylate and aldehyde functionalized } \\
\text { chondroitin sulfate } \\
\text { - NHS-activated chondroitin sulfate and } \\
\text { amine-containing PEG }\end{array}$ & $\begin{array}{l}{[66]} \\
{[67]}\end{array}$ \\
\hline
\end{tabular}


